\title{
Design de Serviço e
}

Moda: relações para o

desenvolvimento de plataformas colaborativas

Maicon Douglas Livramento Nishimura

Doutorando, Universidade Federal de Santa Catarina/ mn.mura@outlook.com

Orcid: 0000-0002-9750-0778/ Lattes

Ricardo Triska

Doutor, Universidade Federal de Santa Catarina / ricardo.triska@ufsc.br

Orcid: 0000-0002-2822-7050/ Lattes

Enviado: 11/12/2020 // Aceito: 25/05/2021 


\title{
Design de Serviço e Moda: relações para o desenvolvimento de plataformas colaborativas
}

\begin{abstract}
RESUMO
O impacto gerado pelo consumo excessivo trouxe, não apenas ao meio ambiente, mas também à sociedade e economia, consequências que questionam a longevidade da espécie humana. Em busca de novas práticas para o desenvolvimento sustentável, percebe-se movimentos pelo mundo, e mais recentemente no Brasil, instigados pelo contexto contemporâneo de inovação e tecnologia, com reflexos para mudança nos processos e nos produtos. Na moda, que careceu de identidade nacional por muitas décadas, verificase o surgimento de plataformas colaborativas de serviços que são disruptivas para o setor. Assim, objetiva-se compreender a relação do design de serviço no desenvolvimento de plataformas colaborativas para o setor da moda brasileira. Para tanto, procede-se à pesquisa de caráter exploratório, de abordagem qualitativa e, como método de levantamento de dados, a pesquisa bibliográfica e documental. Desse modo, observa-se a potencialidade do mercado de moda brasileiro para inovação, quando abordado pelo design de serviço.
\end{abstract}

Palavras-chave: Inovação. Desenvolvimento Sustentável. Economia Criativa. 


\title{
Service Design and Fashion: relationships for the development of colaborative platforms
}

\begin{abstract}
The impact generated by excessive consumption has brought, not only to the environment, but also to society and economy, consequences that question the longevity of the human species. In search of new practices for sustainable development, there are movements around the world, and more recently in Brazil, instigated by the contemporary context of innovation and technology, with consequences for change in processes and products. In fashion, which lacked a national identity for many decades, there is the emergence of collaborative service platforms that are disruptive to the sector. Thus, the objective is to understand the relationship of service design in the development of collaborative platforms for the Brazilian fashion sector. For this purpose, we proceed with exploratory research, with a qualitative approach and, as a method of data collection, bibliographical and documentary research. Thus, the potential of the Brazilian fashion market for innovation is observed, when approached by service design.
\end{abstract}

Keywords Innovation. Sustainable Development. Creative Economy. 


\title{
Diseño de Servicio y Moda: relaciones para el desarrollo de plataformas colaborativas
}

\begin{abstract}
RESUMEN
El impacto que genera el consumo excesivo ha traído, no solo al medio ambiente, sino también a la sociedad y la economía, consecuencias que cuestionan la longevidad de la especie humana. En busca de nuevas prácticas para el desarrollo sostenible, hay movimientos en todo el mundo, y más recientemente en Brasil, instigados por el contexto contemporáneo de innovación y tecnología, con consecuencias para el cambio de procesos y productos. En la moda, que careció de identidad nacional durante muchas décadas, está el surgimiento de plataformas de servicios colaborativos que son disruptivas para el sector. Así, el objetivo es comprender la relación del diseño de servicios en el desarrollo de plataformas colaborativas para el sector de la moda brasileña. Para ello se realiza una investigación exploratoria, con enfoque cualitativo $y$, como método de recogida de datos, una investigación bibliográfica y documental. Así, se observa el potencial de innovación del mercado brasileño de la moda, cuando se aborda desde el diseño de servicios.
\end{abstract}

Palabras clave: Innovación. Desarrolo Sostenible. Economía Creativa. 


\section{INTRODUÇÃO}

A moda, em sua essência, é caracterizada pelo desejo do novo, conforme Lipovetsky relata em "O império do efêmero", em 1989. Porém, em 2020, em sua obra "A sociedade da sedução", afirma que se vive a desestruturação das mais diversas esferas da sociedade, economia, política, educação, cultura, chamada hipermodernidade. Esse contexto é marcado por rituais de sedução, seduzir e agradar, que permeiam desde as relações pessoais até as relações sociais, onde o vestuário de moda, como novidade, perde espaço.

Anterior a este atual período de transição, foram décadas na construção e globalização do ideal de modernidade, que estava baseada no progresso ilimitado, por meio da produção e consumo de bens e serviços, a partir da exploração sistemática da Terra, sem considerar as externalidades do processo (BOFF, 2017). Boff (2017) comenta que houveram benefícios para sociedade, como melhores condições de vida e de saúde, além do encurtamento de distâncias, no entanto, hoje esse modelo é destrutivo ao ser humano.

Em busca de novas práticas para manutenção da espécie humana, em termos ambientais, sociais e econômicos, percebe-se movimentos pelo mundo, e mais recentemente no Brasil, instigados pela consciência ecológica e de consumo, colaborativismo, responsabilidade social e, de modo mais amplo, pelo desenvolvimento sustentável, impulsionado por inovação e tecnologia.

Entre as práticas, verificam-se as plataformas colaborativas que integram designers e/ou empresas para a (co)criação de produtos, compartilhamento de materiais e espaço físico. Assim, objetiva-se compreender a relação do design de serviço no desenvolvimento de plataformas colaborativas para o setor da moda brasileira. 
Para atingir esse objetivo, foi desenvolvida uma pesquisa de caráter exploratório, de abordagem qualitativa e com uso da pesquisa bibliográfica e documental como método de levantamento de dados (GIL, 2010).

O artigo é fundamentado na reflexividade e realismo crítico, isto é, objetiva-se discutir e questionar elementos que são abordados no referencial teórico, por meio da análise de diferentes perspectivas a fim de examinar conceitos estabelecidos ou definidos (ALVESSON; HARDY; HARLEY, 2008), além de procurar tendências, ou falta de regularidades, em dados qualitativos (FLETCHER, 2016).

A revisão narrativa de literatura foi delineada a partir das temáticas da pesquisa, design, serviço, inovação e moda, e se amparou na coleção de artigos de periódicos e livros, sobre moda e sustentabilidade, coletados por um dos autores para elaboração da dissertação de mestrado e, também, durante o período de doutoramento. Soma-se a essa coleção, artigos de periódicos e capítulos de livros, sobre design, serviço e inovação, de contato durante a realização de uma disciplina de [OMITIDO PARA AVALIAÇÃO ÀS CEGAS] do curso de PósGraduação em [OMITIDO PARA AVALIAÇÃO ÀS CEGAS] da [OMITIDO PARA AVALIAÇÃO ÀS CEGAS].

\section{DO DESIGN À MODA}

\subsection{Design}

O design (industrial)

é um processo estratégico de solução de problemas que impulsiona a inovação, gera sucesso nos negócios e leva a uma melhor qualidade de vida através de produtos, sistemas, serviços e experiências inovadoras (WDO, 2020, tradução nossa). 
Mozota, Klöpsch e Costa (2011, p.18) afirmam que

o design, portanto, é um processo de criação e de tomada de decisão. Não é um substituto de outras práticas. Ao contrário, apoia outras atividades e parcerias criativamente com o campo do marketing, empenhando-se em fortalecer e ampliar suas técnicas e capacidades.

Em termos de gestão, Mozota, Klöpsch e Costa (2011) comentam o surgimento da disciplina "gestão de design" (do inglês, design management) na Grã-Bretanha, em meados da década de 1960, que está relacionada à migração de um modelo organizacional vertical taylorista para a adoção de um modelo horizontal e informal, com orientação para o cliente, gerida com base em projetos e na qualidade total. Conforme relatam os autores, as organizações ainda apresentam barreiras à gestão de design por não compreender o propósito da disciplina.

No entanto, antes mesmo de existirem barreiras ao design por parte das organizações, o design possui outras demandas que também merecem atenção. Uma delas é exposto por Dorst (2006), que comenta fazer parte da disciplina de design a solução de problemas, apesar de que não se pode resumila a isso. Desse modo, o autor faz reflexões acerca da teoria de "problemas bem estruturados" (do inglês, well-structured problems) e "problemas mal estruturados" (do inglês, illstructured problems).

A questão em torno dos problemas, segundo Dorst (2006), está no fato de que a teoria sugere, para resolução de um problema bem estruturado, esforços de aprendizado ou redefinição do problema, tornando-o assim, um problema mal estruturado e, consequentemente, obtém-se uma circularidade entre os conceitos. Outro ponto abordado pelo autor é em relação à capacidade do designer em solucionar 
problemas, porque pode ocorrer do sujeito influenciar na formulação do problema.

Nesse sentido, é importante ressaltar princípios que norteiam o design como, por exemplo, do design sócio-técnico (do inglês, Sociotechinical Design), de Cherns (1987). O autor trata o design organizacional como um sistema social e aborda dez princípios: compatibilidade (do inglês, compatibility): o processo precisa ser compatível com seus objetivos; especificação crítica mínima (do inglês, minimal critical specification): transmite-se o que fazer, não como fazer, a fim de não limitar os sujeitos no desenvolvimento do processo; controle de variação (do inglês, variance control): destaque imediato de ineficiências e solicitações de melhorias no processo; localização limite (do inglês, boundary location): deve-se permitir a troca de informações, conhecimentos e aprendizados entre os sujeitos no processo; fluxo de informações (do inglês, information flow): as informações devem ser direcionadas para ação no processo; poder e autoridade (do inglês, power and authority): deve haver equilíbrio para que o sujeito não abuse de seu poder; o princípio multifuncional (do inglês, the multifunctional principle): os sujeitos são capazes de executar múltiplas tarefas; congruência de apoio (do inglês, support congruence): é fornecido suporte social aos sujeitos; organização de transição (do inglês, transitional organization): cria-se uma rede de apoio para o período de transição; incompletude (do inglês, incompletion or the forth bridge principle): o design é caracterizado como um processo em andamento. Ainda, o autor traz os valores (do inglês, values) que em sua concepção faz parte de todos os princípios anteriores. 


\subsection{Serviço}

O conceito de valor recebe grande atenção da disciplina de marketing, devido à sua importância para o mercado, e tem como definição o resultado dos benefícios tangíveis, intangíveis e dos custos financeiros e emocionais relacionados à aquisição de um produto, estabelecendo a relação tríade entre as percepções de qualidade, serviço e preço (KOTLER; KELLER, 2012).

Quando tratado pelo design, o conceito de valor, tem ênfase para suas características intangíveis. Neste artigo é dado enfoque para duas abordagens que versam sobre o assunto, a de "lógica de serviço dominante" (do inglês, service-dominant logic) e de "experiência de serviço" (do inglês, service experience).

A "lógica de serviço dominante", de acordo com Wilden et al. (2017), foi criada há mais de uma década com o objetivo de refletir acerca de serviço em circunstâncias de troca e criação de valor, porém, ainda necessita de maior aprofundamento científico no que concerne ao emergente assunto de inovação. Sob esse ponto de vista, para os autores, isso poderá beneficiar a lógica de serviço dominante, principalmente, a partir de uma abordagem para a inovação aberta (do inglês, open innovation), que integra recursos e criação de valor, por meio de tecnologia e gerenciamento.

Helkkula (2011) comenta que não há consenso entre autores da área para a definição do termo "experiência de serviço", contudo, baseada em uma revisão sistemática de literatura, verificou três caracterizações que a terminologia pode assumir. Conforme a autora, existem caracterizações fenomenológicas (do inglês, phenomenological characterisations), que tratam da experiência de serviço como individualizada, subjetiva e específica, e o sujeito da 
experiência é qualquer ator relevante; caracterizações baseadas em processos (do inglês, process-based characterisations), que abordam as etapas ou fases do processo de serviço e o sujeito da experiência é o cliente; caracterizações baseadas em resultados (do inglês, outcomebased characterisations), que versam sobre a experiência agregada de serviço de vários indivíduos.

\subsection{Inovação}

Para compreender o contexto de inovação, é importante resgatar o conceito de "ciclo de negócios", do também precursor da inovação, Schumpeter (1927). De acordo com o autor, o sistema econômico capitalista não deve ser visto como um ciclo fechado, de altos e baixos, mas como um conjunto de ciclos que movimentam a economia, em que as agitações externas a um ciclo refletem em sua evolução, mas pode gerar a ascensão de um novo ciclo. Em termos de negócios, pode-se imaginar um mercado que atua de maneira estável com um produto em determinado nicho, até que surge outro produto que atenda aquele mesmo nicho e se destaque diante do produto anterior.

Em caracterização a esses ciclos, Schumpeter (1927) demarca períodos em que o capitalismo viveu rompimentos de ciclos e deu origem a outros. Essa demarcação está ilustrada na figura 1 , que apresenta as cinco ondas de Kondratieff, que precede os ciclos de Schumpeter. 
Figura 1. As ondas de Kondratieff e Schumpeter.

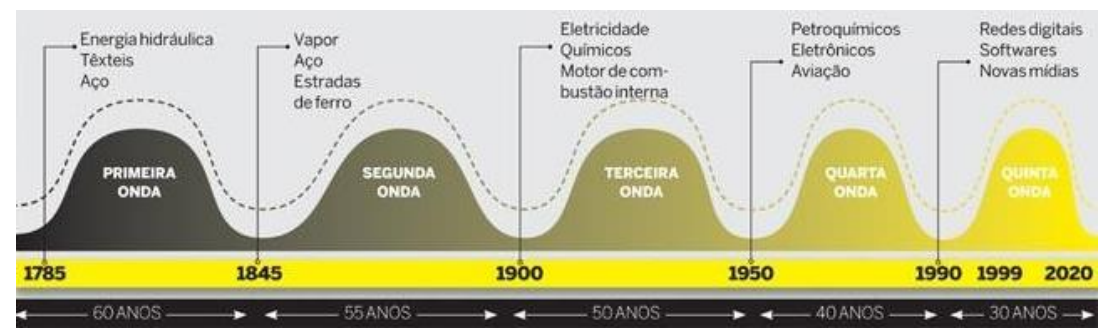

Fonte: InfoMoney (2016). Disponível em: shorturl.at/BHTW5. Acesso em: 11 dez. 2020.

Com base na figura, observa-se que a primeira onda (1785-1844) é marcada pelo desenvolvimento da energia hidráulica, do mercado têxtil e de aço. Em seguida, na segunda onda (1845-1899), o destaque vai para a energia a vapor e a construção de estradas de ferro. Já na terceira onda (1900-1949), a energia elétrica, químicos e o motor à combustão interna, alavancam a indústria. A quarta onda (1950-1989) é representada pelo progresso da indústria petroquímica, de equipamentos eletrônicos e da aviação. A quinta onda (1990), tem sido assinalada pelo desenvolvimento tecnológico e pelas redes digitais.

Em paralelo às ondas, é interessante observar as eras da inovação abordadas por Anthony (2012b). Conforme o autor, até o momento, existiram quatro eras, sendo a primeira chamada de "inventor solitário" (antes de 1915), em que a invenção e o indivíduo que a criou estão interligados, por exemplo, a imprensa de Gutenberg; a segunda era, em que as invenções são realizadas em laboratórios e de responsabilidade de grandes empresas, por exemplo, o nylon da Dupont; a terceira era, em que a burocratização das grandes empresas levou seus próprios funcionários a empreenderem, apoiados pelo capital de risco, por exemplo, a Microsoft; e a quarta era (até os dias de hoje) em que deve haver uma mudança nos modelos de negócios devido ao ritmo acelerado do mercado. 
De fato, o início e o fim de um ciclo são marcados por inovações. Nesse sentido, inovação pode ser definida como

o processo de diferentes estágios pelo qual as organizações transformam ideias em novos produtos, serviços ou processos, a fim de avançar, competirem e diferenciarem-se com sucesso em seus mercados (BARAGHEH; ROWLEY; SAMBROOK, 2009, p.1334, tradução nossa).

Assim, é possível observar que esse conceito está interligado ao de ciclo de negócios de Schumpeter, por tratar de diferenciação para competição em nicho de mercado.

A inovação na prática pode adquirir formatos diferentes e, a partir disso, Anthony (2012a) estabelece duas categorias, sendo a primeira focada no tipo de inovação e a segunda no objeto da inovação. Para o autor, a inovação pode ser, estratégica comercial: em que se buscam novas formas de comercializar e promover um produto existente; sustentada: em que se incrementa produtos e serviços que já existem; transformacional: em que se introduz um avanço de desempenho em categoria de produto existente; e disruptiva: em que se cria uma nova categoria de produto. $E$, em relação ao objeto, o autor define: novos produtos, distribuição, novos modelos de receita e processos.

Em termos de produtos, a IDEO, empresa global de design e inovação, descreve sua metodologia de desenvolvimento em cinco etapas, são elas:

entender o mercado, o cliente, a tecnologia e as restrições percebidas sobre o problema; observar as pessoas reais em situações da vida real para descobrir o que as motiva; visualizar conceitos novos para o mundo e os clientes que os usarão; avaliar e refinar os protótipos em uma série de interações rápidas; e implementar o novo conceito de comercialização (KELLEY; LITMAN, 2011, p.17-18, tradução nossa). 
Ainda, quando se trata de inovação, é relevante abordar a inovação aberta. Segundo Myhren et al. (2018, p. 101, tradução nossa), "a inovação aberta aproveita o conhecimento externo e o acesso a novos canais de mercado para o desenvolvimento de produtos e serviços". E, ao tratar de serviços, os autores, embasado na literatura, definem duas categorias de inovação: incremental e radical.

Myhren et. al. (2018, p. 102, tradução nossa) definem a inovação aberta de serviço incremental como "as combinações de recursos que melhoram o desempenho de acordo com as características existentes", enquanto a inovação aberta de serviço radical é representada por "combinações de recursos que aprimoram o desempenho por meio de um novo conjunto de características". Isto é, utilizar os recursos disponíveis para aperfeiçoar ou criar serviços inteiramente novos.

\subsection{Moda}

A moda em termos de desejo pelo novo remete à ideia de incitação à novidade, que culmina em relações efêmeras entre pessoas, produtos ou serviços (LIPOVETSKY, 1989; CIDREIRA, 2005; SANT'ANNA, 2007), e no que diz respeito ao vestuário, refere-se à construção do sistema de moda, que tem como alicerce o conceito anterior.

O sistema de moda é datado da segunda metade da Idade Média, na Europa medieval e, aproximou-se do formato atual no final do século 19, com Worth, em Paris (LIPOVETSKY, 1989). Para Lipovetsky (1989), o estilista disciplinou o setor de vestuário de moda por instituir desfiles e definir calendário divididos em estações, mas, sobretudo, disseminou a ideia de (vestuário de) moda como tendência ao estimular o desejo pelo consumo. 
Em resumo, o sistema de moda tratado por Lipovetsky (1989) pode ser divididos em quatro fases, são elas: moda aristocrática, período de transição entre aristocracia e burguesia; moda dos cem anos, período em que se estabelece o sistema de moda; moda aberta, período de disseminação do estilo da alta costura por meio do "pronto para vestir" (do francês, prêt-à-porter); e moda consumada, período de coletivização do sistema de moda.

Pode-se incluir ainda no sistema de moda, uma fase contemporânea, da moda rápida (do inglês, fast fashion), período em que coexistem os estilos que vão da alta costura à coletivização, sob um contexto efêmero de consumo (GWILT, 2014), que visa reduzir o ciclo de vida do produto para entregar novidades ao consumidor, em um curto intervalo de tempo e a um preço baixo (SALCEDO, 2014).

Porém, a fim de se equacionar custo, tempo e qualidade, é necessário realizar sacrifícios que geram consequências de impacto ao meio ambiente, sociedade e economia. Assim, as abordagens sustentáveis alcançam o setor da moda com o intuito de trazer reflexões sobre essas questões e ressignificar o sistema de moda vigente.

No que concerne à moda brasileira, durante muitas décadas, é evidente a cópia de padrões estéticos europeus com adaptação ao clima, devido à falta de uma trajetória cultural que desse impulso à criação, mesmo após o desenvolvimento tecnológico têxtil a partir da década de 1920 (NEIRA, 2008). Entre altos e baixos, a moda brasileira, na década de 1970 entra em uma onda nacionalista, motivada pelo tropicalismo; na década de 1980 é marcada pelo crescimento da indústria têxtil nas figuras de jovens estilistas, hoje consagrados; na década de 1990 despontam os eventos de moda e a profissionalização da área por meio da institucionalização de cursos de moda; na década de 2000 em 
diante adquire identidade no mercado mundial pela moda praia, surfwear e jeanswear (LEITÃO, 2007).

\subsubsection{Desenvolvimento sustentável}

Na década de 1960, Rachel Carson fez história ao evidenciar o uso excessivo de agrotóxicos e suas consequências para o meio ambiente por meio da publicação do livro "Primavera Silenciosa", em 1962. A partir desse período, a discussão sobre desenvolvimento sustentável, que era essencialmente filosófica e acadêmica, ganha espaço entre a sociedade civil (LEIS, 2004).

Para tratar de desenvolvimento sustentável é importante primeiramente esclarecer o que o distingue do conceito de sustentabilidade. Veiga $(2010 ; 2015)$ reforça haver, nos últimos anos, a banalização da "sustentabilidade" pelo mercado e afirma que não existe consenso e clareza na definição do termo, afinal, envolve diversas variáveis e pontos de vista. No entanto, o autor caracteriza a noção de sustentabilidade de Amartya Sen como a mais aceitável. Apoiado na ideia do Relatório de Brundtland, de atender as necessidades das gerações atuais sem comprometer a capacidade das futuras, faz um adendo às "necessidades" a partir da percepção de um ser humano dotado de valores, com liberdade para decidir e reagir além de suas necessidades (VEIGA, 2010).

Já a noção de desenvolvimento sustentável está pautada na "possibilidade e a esperança de que a humanidade poderá, sim, se relacionar com a biosfera de modo a evitar os colapsos profetizados nos anos 1970" (VEIGA, 2015, p.46). Nesse sentido, Elkington (2001) desenvolve a metodologia do Triple Bottom Line, que caracteriza o desenvolvimento sustentável 
como o equilíbrio das dimensões ambiental, econômica e social da sustentabilidade.

De modo geral, o conceito de sustentabilidade se baseia na percepção de uma dinâmica natural do planeta, em que mudanças são inevitáveis e o ser humano pouco ou nada pode fazer, enquanto o conceito de desenvolvimento sustentável concebe um ideal coletivo de humanidade (VEIGA, 2015).

Em termos de (vestuário de) moda, existe muita expectativa devido à capacidade do sistema de antecipar o futuro, interpretar as demandas e responder às necessidades por meio de práticas sustentáveis e de alto valor agregado (HETHORN; ULASEWICZ; 2008; LEE, 2009).

Para esquematizar as questões que envolvem o desenvolvimento sustentável no setor da moda, Salcedo (2014) faz o levantamento dos impactos ambiental e social do ciclo de vida de um produto de moda (Tabela 1), que torna evidente o impacto negativo relacionado ao uso de produtos químicos, suas consequências para a saúde do ser humano, geração de resíduos e as condições insalubres de trabalho.

Tabela 1. Impactos das fases do ciclo de vida.

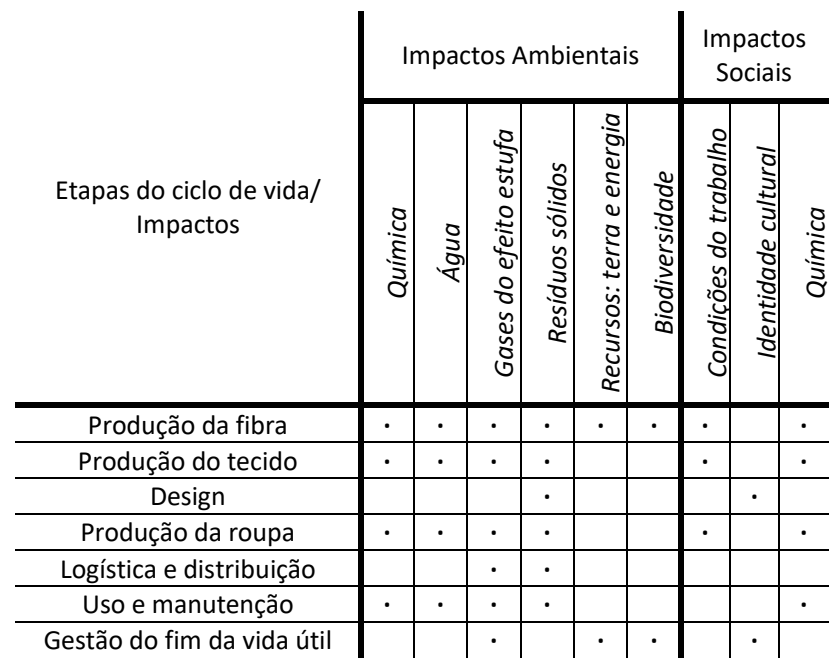

Fonte: Salcedo (2014, p. 30). 
Em contraponto, com o intuito de minimizar os efeitos negativos da indústria, surgiram movimentos no sentido de promover uma moda ética, ecológica e até uma nova proposta de sistema, o slow fashion. A moda ética adota uma postura consciente em relação ao meio ambiente e às pessoas envolvidas, tanto trabalhadores como os consumidores (SALCEDO, 2014; SCHULTE, 2015). A ecomoda ou moda ecológica, tem como intenção a redução do impacto ambiental, por exemplo, pelo uso de técnicas de reciclagem (LEE, 2009; SALCEDO, 2014). E o slow fashion vem para sugerir uma reflexão no ritmo de consumo e apoiar uma produção pautada para qualidade, preço justo e valorização dos indivíduos (FLETCHER; GROSE, 2011).

\subsubsection{Economia criativa}

Outro movimento que merece destaque é o da economia criativa. De acordo com a UNCTAD (2010), não existe uma definição única para o termo, no entanto, segundo o "Relatório de Economia Criativa 2010", este "é um conceito em evolução baseado em ativos criativos que potencialmente geram crescimento e desenvolvimento econômico (UNCTAD, 2010, p.10)". No mesmo documento, caracteriza-se como parte dessa classe

\footnotetext{
pessoas que fazem parte dos campos da ciência e engenharia, arquitetura e design, educação, artes, música e entretenimento, cuja função é criar ideias, novas tecnologias e conteúdos criativos (UNCTAD, 2010, p.11).
}

Ou seja, o propósito da economia criativa é dar atenção à criatividade como meio econômico, desmitificando que desenvolvimento cultural e econômico não pode acontecer de modo simultâneo (UNCTAD, 2010). 
Ceglia (2020) cita que economia criativa é o setor composto pelas indústrias criativas, em que a criatividade tem influenciado diversas categorias de iniciativas, por meio de trocas culturais, em esfera local e global, resultando em uma nova classe de trabalho. Para o autor, a realidade brasileira, em que carece de políticas e ações delineadas para o setor, desenvolve-se tanto no contexto formal e informal, mas necessita de conhecimento, habilidade e experiência para sua ampliação.

No contexto da indústria da moda, que se enquadra na indústria criativa pelo uso da criatividade e capital intelectual como fonte de criação, produção e distribuição de bens e serviços, destaca-se o reuso de materiais têxteis por meio de técnicas de reciclagem, como o upcycling (CEGLIA, 2020). O upcycling é caracterizado pela reutilização de materiais sem consumo energético, porém, com a entrega de um produto de qualidade superior devido às intervenções artesanais ou pelo história envolvida no produto (FLETCHER, 2014; GWILT, 2014; SALCEDO, 2104; BERLIM, 2016).

\subsubsection{Plataformas colaborativas}

Nesse contexto de economia criativa, desenvolvimento sustentável, inovação, serviço e design, também despontam as plataformas colaborativas. Em um primeiro momento, essas plataformas se destacam no ensino, como meio de promover a gestão do conhecimento, tomam a sociedade, por intermédio das redes sociais, e chegam no meio corporativo (BRIEDE et al., 2016).

A nível de organizações, as plataformas colaborativas são caracterizadas, como ferramentas para o desenvolvimento de práticas de inovação no desenvolvimento de novos produtos, por possibilitar o gerenciamento de conhecimento dos 
stakeholders envolvidos no projeto (BUENO; BALESTRIN, 2012).

No cenário de moda, os laboratórios de moda ou Fashion Labs (do inglês, Fashion Laboratories), surgem a partir da descentralização da indústria tradicional e estabelece um espaço tecnológico, democrático e propício para inovação, com foco para o desenvolvimento de moda e vestuário (FELIPPE et al., 2020), com proposta análoga às plataformas colaborativas.

Um exemplo de destaque na moda brasileira é a plataforma de rede colaborativa "A Malha", que surgiu "como uma possibilidade de repensar e recriar o mercado da moda (MALHA, 2020)". Essa rede está estruturada com base em espaços de coworking, trazendo uma reorganização do sistema de moda, uma nova proposta de modelo de negócio, além de sua essência sustentável (BARCELLOS, 2018).

Outro exemplo de plataforma colaborativa no Brasil é o "Lab Moda Sustentável", parceria entre a Organização Internacional do Trabalho (OIT), Associação Brasileira da Indústria Têxtil e de Confecção (ABIT), Associação Brasileira do Varejo Têxtil (ABVTEX), Instituto C\&A, Fundação Hermann Hering, Santista S.A. e Reos Partners, com o objetivo de debater e propor soluções para os desafios do mercado de moda nacional (ABIT, 2020).

E na realidade do estado de Santa Catarina, destaca-se a plataforma colaborativa Santa Catarina Moda e Cultura (SCMC), que

conecta empresas e universidades para capacitar pessoas, fomentar inovação, estimular ambientes pulsantes e ressignificar protagonismos (SCMC, 2020).

Sob essa conjuntura, de integração para o desenvolvimento de produto, é importante destacar o papel 
conciliador do responsável por essa função, no caso deste artigo, o designer de moda, pelo domínio de conhecimentos que serão determinantes para o desenvolvimento sustentável de produtos (GWILT, 2014).

\title{
3. RELAÇÕES ENTRE DESIGN, SERVIÇO, INOVAÇÃO E MODA
}

Para a Organização Mundial de Design

\begin{abstract}
o Design Industrial oferece uma maneira mais otimista de olhar para o futuro, reformulando os problemas como oportunidades. Ele une inovação, tecnologia, pesquisa, negócios e clientes para fornecer novo valor e vantagem competitiva nas esferas econômica, social e ambiental (WDO, 2020, tradução nossa).
\end{abstract}

Mozota, Klöpsch e Costa (2011) afirmam que é função da gestão de design atuar na integração desses pilares, afinal, gerenciar a "inovação orientada ao design" (do inglês, designdriven innovation) implica no gerenciamento da interação dos atores envolvidos no processo, pelo acesso e processamento de seus conhecimentos em produtos, a fim de gerar mudanças e influenciar modelos socioculturais (VERGANTI, 2008).

Como uma vertente do design, assim como a gestão de design e a inovação orientada ao design, o "design de serviço" (do inglês, design service) é caracterizado pelo

$$
\begin{aligned}
& \text { processo de design coletivo e contínuo que } \\
& \text { envolve atores na criação, interrupção e } \\
& \text { manutenção de arranjos institucionais para } \\
& \text { permitir o valor no contexto (VINK et al., 2017, } \\
& \text { p.05, tradução nossa). }
\end{aligned}
$$

Sob uma lógica de "design para serviço" (do inglês, design for service), com foco para co-criação de valor, 
desenvolvimento de novos serviços e inovação, influenciada por diversas abordagens de design, como design thinking e design centrado no usuário (do inglês, user-centered design), cria-se então o design de serviço (YU; SANGIORGI, 2017).

Ressalta-se os diversos momentos em que os termos "design" e "inovação" aparecem juntos no decorrer do artigo, ora pertencendo, ora complementando seus conceitos. Seja o design como processo de criação ou de solução de problemas, bem ou mal estruturados, deve ser destacado pelo seu aspecto social e de desenvolvimento contínuo, que em contexto de inovação, aberta ou fechada, incremental ou radical, permite (co)criar valor e gerar mudanças em modelos socioculturais com vista para o desenvolvimento sustentável.

Ao tratar de inovação, o reconhecimento das ondas de Kondratieff remetem ao processo de ciclo de vida de um produto que é determinado pelo seu valor. O valor, como conceito para o design, adquire um caráter subjetivo, porém, possui um papel social fundamental nessa linha do tempo ao impulsionar ou extinguir um produto/serviço.

Ao analisar a moda (brasileira) e o design de serviço, percebe-se uma lacuna a ser preenchida dada as demandas do setor por criação de valor, via identidade cultural, e desenvolvimento sustentável. Reflexo disso é o surgimento de Fashion Labs/plataformas colaborativas que despontam como soluções alternativas ao estabelecer novos modelos de negócios, que possibilitam a abertura de canais diretos entre os diferentes stakeholders, exaltando as problemáticas do setor em respeito ao meio ambiente, sociedade, economia e cultura. Do mesmo modo, mas em contexto genérico, há o movimento de economia criativa que caminha para o mesmo fim, a inovação.

Os Fashion Labs/plataformas colaborativas possuem em sua origem a inovação, seja ela de produto, processo, 
marketing ou organizacional, além de estimular o design autoral pelo processo de experiência, compartilhamento e prototipagem oferecidos por esses espaços de (co)criação (FELIPPE et al., 2020). Desse modo, as plataformas colaborativas são resultado da interdisciplinaridade entre design de serviço, moda e inovação, dentro da realidade da economia criativa.

\section{CONSIDERAÇÕES FINAIS}

Os caminhos da inovação são claros e parecem definitivos ao demarcarem mudanças pontuais na história, que pressionam instituições, como mercado e sociedade, na geração de novos conhecimentos. Por exemplo, em marketing, a inovação em serviço teve papel fundamental na ressignificação do produto. Assim como no design, em que a abordagem centrada no ser humano e para 0 desenvolvimento sustentável atua na reconfiguração processos e produtos.

Assim, percebe-se que o design de serviço se relaciona com o desenvolvimento de plataformas colaborativas no setor da moda brasileira, porque proporciona o desenvolvimento de novos modelos de negócios e o deslocamento do eixo do sistema de moda para um desenvolvimento mais sustentável e com enfoque no ser humano. Igualmente, sob a perspectiva da inovação, esses movimentos podem ser considerados pontos de disrupção para o mercado nacional.

As limitações desta pesquisa se baseiam no estudo de plataformas colaborativas no contexto da moda, com enfoque para design de serviço, inovação e desenvolvimento sustentável. Além disso, é importante ressaltar o uso recente do termo "plataformas colaborativas" no panorama da moda, 
o que pode ter excluído termos sinônimos que não apareceram nas buscas por motivo de terminologia.

Por fim, em recomendação a pesquisas futuras, sugere-se a caracterização detalhada do contexto de plataformas colaborativas no âmbito da moda, nacional e internacionalmente, além da investigação e aprofundamento da relação entre "objetivos de desenvolvimento sustentável" (ODS) e "plataformas colaborativas", temáticas destaques durante o levantamento desta pesquisa devido seu caráter contemporâneo.

\section{REFERÊNCIAS}

ABIT - Associação Brasileira da Indústria Têxtil e de Confecção. Conheça o Lab Moda Sustentável, plataforma de colaboração e inovação do setor. 2019. Disponível em:https://www.abit.org.br/noticias/conheca-o-lab-modasustentavel-plataforma-de-colaboracao-e-inovacao-do-setor. Acesso em: $11 \mathrm{dez} .2020$.

ALVESSON, M.; HARDY, C.; HARLEY, B. Reflecting on reflexivity: reflexive textual practices in organization and management theory. Journal of Management Studies, v. 45, n. 3, p.480-501, abr. 2008. Disponível em: https://doi.org/10.1111/j.14676486.2007.00765.x. Acesso em: 11 dez. 2020.

ANTHONY, S. The little black book of innovation: how it works, how to do it. Boston: Harvard Business Review Press, 2012a.

ANTHONY, S. The new corporate garage. Harvard Business Review, v. 90, n. 9, p. 44-53, 2012b.

BARCELLOS, L. Novos modelos de negócio de moda sustentável, estudo de caso da plataforma colaborativa: malha. 2018. Dissertação (Mestrado) - Universidade do Minho, Escola de Engenharia, Programa de Pós-Graduação em Design Têxtil, Guimarães, 2018. Disponível em: http://repositorium.sdum.uminho.pt/handle/1822/60373. Acesso em: 11 dez. 2020.

BAREGHEH, A.; ROWLEY, J.; SAMBROOK, S. Towards a multidisciplinary definition of innovation. Management Decision, v. 47, n. 8, p.1323-1339, set. 2009. Disponível em: http://dx.doi.org/10.1108/00251740910984578. Acesso em: 11 dez. 2020.

BERLIM, L. Moda e sustentabilidade: uma reflexão necessária. São Paulo: Estação das Letras e Cores, 2016.

BOFF, L. Sustentabilidade: o que é: o que não é. Petrópolis: Vozes, 2017. 
BRIEDE, J.; CABELlO, M.; PÉREZ, C.; ARRIAGAdA, A. Plataforma colaborativa para la gestión de proyectos de diseño industrial. Formácion Universitaria, v. 9, n. 3, p.61-74, 2016. Disponível em: http://dx.doi.org/10.4067/s0718-50062016000300008. Acesso em: 11 dez. 2020.

BUENO, B.; BALESTRIN, A. Inovação colaborativa: uma abordagem aberta no desenvolvimento de novos produtos. Revista de Administração de Empresas, v. 52, n. 5, p.517-530, set./out. 2012. Disponível em: http://www.scielo.br/pdf/rae/v52n5/a04v52n5.pdf. Acesso em: 11 dez. 2020.

CEGLIA, D. Uma análise complexa e rizomática da indústria da moda: em direção a uma economia criativa circular. 2020. 221 p. Tese (Doutorado) - Universidade Federal do Rio Grande do Sul, Escola de Administração, Programa de Pós-Graduação em Administração, Rio Grande do Sul, 2020. Disponível em: https://lume.ufrgs.br/handle/10183/207039. Acesso em: 12 jun. 2021.

CHERNS, A. Principles of sociotechnical design revisted. Human Relations, v. 40, n. 3, p.153-161, mar. 1987. Disponível em: https://doi.org/10.1177/001872678704000303. Acesso em: 11 dez. 2020.

CIDREIRA, R. Os sentidos da moda: vestuário, comunicação e cultura. São Paulo: Annablume, 2005.

DORST, K. Design problems and design paradoxes. Design Issues, v. 22, n. 3, p.4-17, jul. 2006. Disponível em: https://doi.org/10.1162/desi.2006.22.3.4. Acesso em: $11 \mathrm{dez}$. 2020.

ELKINGTON, J. Canibais com garfo e faca. São Paulo: Makron Books, 2001.

FELIPPE, A.; RECH, S.; SILVEIRA, I.; ROSA, L. Fashion lab como fator de inovação no design autoral de moda. ModaPalavra, v. 13, n. 30, p.9-39, out./dez. 2020. Disponível em: https://www.periodicos.udesc.br/index.php/modapalavra/article/vi ew/18768/12047. Acesso em: 23 jun. 2021.

FLETCHER, A. Applying critical realism in qualitative research: methodology meets method. International Journal of Social Research Methodology, v. 20, n. 2, p.181-194, fev. 2016. Disponível em: https://doi.org/10.1080/13645579.2016.1144401. Acesso em: $11 \mathrm{dez} .2020$.

FLETCHER, K., GROSE, L. Moda \& sustentabilidade: design para mudança. São Paulo: Senac, 2011.

FLETCHER, K. Sustainable fashion and textiles. London: Routledge, 2014.

GIL, A. Como elaborar projetos de pesquisa. 5. ed. São Paulo: Atlas, 2010.

GWILT, A. Moda sustentável: um guia prático. São Paulo: Gustavo Gili, 2014. 
HELKKULA, A. Characterising the concept of service experience. Journal of Service Management, v. 22, n. 3, p.367-389, jun. 2011. Disponível: https://doi.org/10.1108/09564231111136872. Acesso em: 11 dez. 2020.

HETHORN, J., ULASEWICZ, C. Sustainable fashion: why now? A conversation about issues, practices, and possibilities. New York: Fairchild Books, 2008.

KELLEY, T.; LITTMAN, J. The art of innovation: lessons in creativity from IDEO, America's leading design firm. New York: Doubleday, 2011.

KOTLER, P.; KELLER, K. L. Administração de marketing. 14. ed. São Paulo: Pearson Education, 2012.

LEE, M. Eco chic: o guia de moda ética para a consumidora consciente. São Paulo: Larousse do Brasil, 2009.

LEIS, $H$. A modernidade insustentável: as críticas do ambientalismo à sociedade contemporânea. 2 ed. Montevideo: Coscoroba, 2004.

LEITÃO, D. Brasil à moda da casa: imagens da nação na moda brasileira contemporânea. 2007. 373 p. Tese (Doutorado) Universidade Federal do Rio Grande do Sul, Instituto de Filosofia e Ciências Humanas, Programa de Pós-Graduação em Antropologia Social, Rio Grande do Sul, 2007. Disponível em: https://lume.ufrgs.br/handle/10183/10252. Acesso em: $11 \mathrm{dez}$. 2020.

LIPOVETSKY, G. O império do efêmero: a moda e seus destinos nas sociedades modernas. São Paulo: Companhia das Letras, 1989.

LIPOVETSKY, G. A sociedade da sedução: democracia e narcisismo na hipermodernidade liberal. Barueri: Manole, 2020.

MALHA. História. $2020 . \quad$ Disponível em:https://www.malha.cc/historia. Acesso em: 11 dez. 2020.

MOZOTA, B.; KLÖPSCH, C.; COSTA, F. Gestão do design: usando o design para construir valor de marca e inovação corporativa. Porto Alegre: Bookman, 2011. 343p.

MYHREN, P.; WITELL, L.; GUSTAFSSON, A.; GEBAUER, $H$. Incremental and radical open service innovation. Journal of Services Marketing, v. 32, n. 2, p.101-112, abr. 2018. Disponível em: https://doi.org/10.1108/JSM-04-2016-0161. Acesso em: 11 dez. 2020.

NEIRA, L. A invenção da moda brasileira. Caligrama, v. 4, n. 1, abr. 2008. Disponível em: http://dx.doi.org/10.11606/issn.18080820.cali.2008.68123. Acesso em: $11 \mathrm{dez} .2020$.

SALCEDO, E. Moda ética para um futuro sustentável. São Paulo: Gustavo Gili, 2014.

SANT 'ANNA, M. Teoria de moda: sociedade, imagem e consumo. São Paulo: Estação das Letras, 2007.

SCHUMPETER, J. The explanation of the business cycle. Economica, v. 21, n. 21, p.286-311, dez. 1927. 
SCHULTE, N. Reflexões sobre moda ética: contribuições do biocentrismo e do veganismo. Florianópolis: Editora da UDESC, 2015. 160 p.

SCMC - Santa Catarina Moda e Cultura. Página inicial. 2020. Disponível em: https://www.scmc.com.br. Acesso em: 11 dez. 2020.

WILDEN, R.; AKAKA, M.; KARPEN, I.; \& HOHBERGER, J. The evolution and prospects of service-dominant logic: an investigation of past, present, and future research. Journal of Service Research, v. 20, n. 4, p.345-361, jul. 2017. Disponível em: https://doi.org/10.1177/1094670517715121. Acesso em: $11 \mathrm{dez}$. 2020.

WDO - World Design Organization. Definition of industrial design. 2020. Disponível em: https://wdo.org/about/definition/. Acesso em: 11 dez. 2020.

YU, E.; SANGIORGI, D. Service design as an approach to implement the value cocreation perspective in new service development. Journal of Service Research, v. 21, n. 1, p.40-58, mai. 2017. Disponível em: https://doi.org/10.1177/1094670517709356. Acesso em: $11 \mathrm{dez} .2020$.

UNCTAD - United Nations Conference on Trade and Development. Relatório de economia criativa 2010, 2010. Disponível em: https://unctad.org/pt/docs/ditctab20103_pt.pdf. Acesso em: $11 \mathrm{dez} .2020$.

VEIGA, J. Desenvolvimento sustentável: o desafio do século XXI. Rio de Janeiro: Garamond, 2010.

VEIGA, J. Para entender desenvolvimento sustentável. São Paulo: Editora 34, 2015.

VERGANTI, R. Design, meanings, and radical innovation: a metamodel and a research agenda. Journal of Product Innovation Management, v. 25, n. 5, p.436-456, set. 2008. Disponível em: https://doi.org/10.1111/j.15405885.2008.00313.x. Acesso em: $11 \mathrm{dez} .2020$.

VINK, J.; TRONVOLL, B.; EDVARDSSON, B.; WETTER-EDMAN, K.; AGUIRRE, M. Service ecosystem design: doing institutional work through service design. Proceedings of the Naples Forum on Service, p.1-15, 2017. 